\title{
Imaging struma ovarii by means of 124I-Na PET/CT
}

Egesta Lopci, Paolo Colombo², Marcello Rodari', Andrea Lania ${ }^{2}$, Domenico Vitobello ${ }^{3}$, Lorenzo Leonardi', Arturo Chiti ${ }^{1}$

${ }^{1}$ Nuclear Medicine Unit, IRCCS Humanitas, Italy 2Department of Endocrinology, IRCCS Humanitas, Italy ${ }^{3}$ Gynaecology Unit, IRCCS Humanitas, Italy

[Received 5 III 2013; Accepted 10 VI 2013]

\section{Abstract}

Struma ovarii is a rare form of ovary tumour defined as the presence of ectopic thyroid tissue in the ovarian structures. It usually presents with a benign course, although in some cases carcinoma or other malignant tumours can be found in the context of the ectopic tissue. Herein we report the case of a young patient affected by struma ovarii visualized by means of 124I-Na $\mathrm{PET} / \mathrm{CT}$. Thanks to the excellent target-to-background ratio of the tracer and the high resolution of the method, we could well identify the presence of some minimal tumour at the level of the left ovary. To our knowledge, this is the first report of its kind. KEY words: struma ovarii, 124I-Na, positron emission tomography, PET, PET/CT

Nuclear Med Rev 2013; 16, 2: 95-96

\section{Case report}

Struma ovarii is a rare form of ovary tumour, accounting for $1 \%$ of the ovarian neoplasia, and defined as the presence of ectopic thyroid tissue in the ovarian structures [1]. It usually presents with a benign course, although in some cases carcinoma or other malignant tumours can be found in the context of the ectopic tissue [2, 3].

Herein we report the case of a young patient affected by struma ovarii, which was incidentally diagnosed during a caesarean delivery. Our 29 year-old patient had the removal of an ovarian cyst dur-

Correspondence to: Egesta Lopci MD

Nuclear Medicine department, Humanitas Clinical and Research Centre

Via Manzoni, 56 (Rozzano), IT-20089 Milano

Tel.: + 390282247542

Fax: +390282246693

E-mail: egesta.lopci@gmail.com, egesta.lopci@cancercenter.humanitas.it
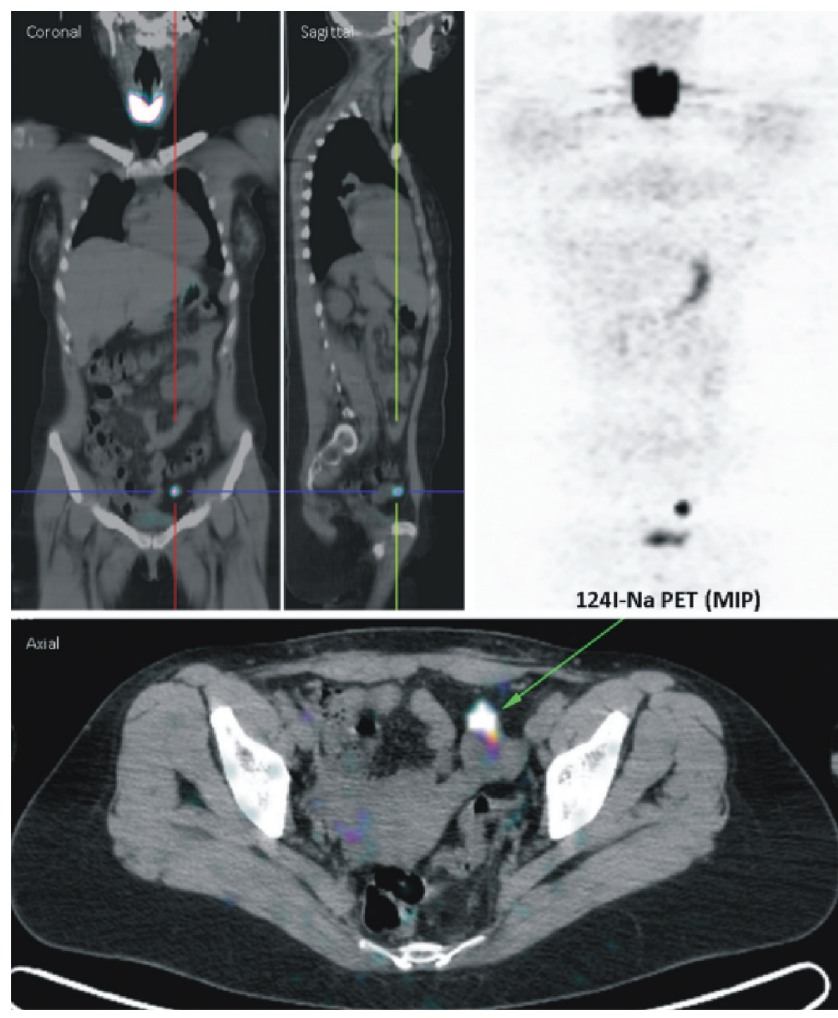

Figure 1. Maximal Intensity Projection (MIP) image of 124I-Na PET/CT and fused coronal, sagittal and axial sections, showing the ectopic tissue present in the left ovary (arrow); for the study the patient received an I.V. injection of $212 \mathrm{MBq}(5.7 \mathrm{mCi})$ of $124 \mathrm{I}-\mathrm{Na}$, and images were acquired 24 hours later ( $T_{1 / 2} 4.2$ days) by means of a $3 \mathrm{D}$ PET/CT tomograph (Siemens Biograph 6 LSO: $3.5 \mathrm{~min} /$ bed position, $128 \times 128$ matrix, zoom 1.0, $95 \mathrm{mAs}, 130 \mathrm{kV}$ and $5 \mathrm{~mm}$ collimation $6 \times 3 \mathrm{~mm}$ for the localization CT; OSEM iterative algorithm). Along with the pathologic tracer accumulation, we could also identify some physiologic uptake in the thyroid gland, as well as in the stomach and in the bladder, due to salivary and urinary excretion

ing the delivery and histology showed a well-differentiated papillary carcinoma of thyroid origin. Specific investigations of the thyroid gland, including ultrasound, made the possibility of malignant transformation of the eutopic tissue unlikely, thus suggesting that the degeneration found in the struma ovarii had an in-loco origin (non-metastatic). Before undergoing further treatment [4, 5], we decided to perform a total-body PET/CT scan with 124I-Na (Figure 1). Thanks to the excellent target-to-background ratio of the tracer and 
the high resolution of the method $(\sim 0.5 \mathrm{~cm})$, we could well identify the presence of some minimal tumour residue (diameter $=0.6 \mathrm{~cm}$; ki67 25\%) at the level of the left ovary (arrow). This could not be imaginable with other methods, including total-body 123/1311-Na scan, because of the suboptimal resolution $(1.0-1.5 \mathrm{~cm})$ or CT/MR, because of the inadequate specificity.

To our knowledge, this is the first report of its kind, documenting the presence of struma ovarii by means of 124I-Na PET/CT.

\section{References}

1. Utsunomiya D, Shiraishi S, Kawanaka K et al. Struma ovarii coexisting with mucinous cystadenoma detected by radioactive iodine. Clin Nucl Med 2003; 28: 725-727.

2. Makani S, Kim W, Gaba AR. Struma ovarii with a focus of papillary thyroid cancer: a case report and review of the literature. Gynecol Oncol 2004; 94: 835-839.

3. Bal A, Mohan H, Singh SB, Sehgal A. Malignant transformation in mature cystic teratoma of the ovary: report of five cases and review of the literature. Arch Gynecol Obstet 2007; 275: 179-182.

4. DeSimone CP, Lele SM, Modesitt SC. Malignant struma ovarii: a case report and analysis of cases reported in the literature with focus on survival and 1131 therapy. Gynecol Oncol 2003; 89: 543-548.

5. Robboy SJ, Shaco-Levy R, Peng RY, Snyder MJ, Donahue J, Bentley RC Malignant struma ovarii: an analysis of 88 cases, including 27 with extraovarian spread. Int J Gynecol Pathol 2009; 28: 405-422. 